\title{
Protective Effect of Peanut (Arachis Hypogaea L.) and Its Combination with Propranolol in Cardiotoxic Rats
}

\author{
Farah Naz ${ }^{1}$, Nasim Jahan ${ }^{2}$, Nayma Sultana ${ }^{3}$
}

\begin{abstract}
Background: Cardiotoxicity (CT) can be developed due to prolonged use of higher doses of some drugs, exposure to some chemicals, toxins or infectious agents and also by some disease conditions. Natural plant foods such as peanut (Arachis hypogaea L.) may have free radical scavenging activity, thereby can be used for the prevention and management of heart disease. Objective: To observe the protective effect of peanut (Arachis hypogaea L.) and its combined action with propranolol on histological changes in isoproterenol induced cardiotoxic rats. Method: This experimental study was carried out in the Department of Physiology, Sir Salimullah Medical College, Dhaka in 2012. For this purpose, 20 Wistar albino rats, age 85- 100 days, weighing 120 to $150 \mathrm{~g}$ (initial body weight) were included in the peanut treated group. They were sub-divided into CT-ISO-P (Cardiotoxic group with isoproterenol after peanut treatment) and CT-ISO-C (Cardiotoxic group with isoproterenol after combined treatment of peanut and propranolol). Age and weight matched 30 Wistar albino rats without any peanut supplementation were taken and sub-divided into three sub-groups, $\mathrm{BC}$ (Baseline control), CT-ISO (Cardiotoxic group with isoproterenol) and CT-ISO-PRO (Cardiotoxic group with isoproterenol after propranolol treatment). Each sub-group consisted of 10 rats. After taking final body weight all the rats were sacrificed on $22^{\text {nd }}$ day. The heart was removed and preserved in $10 \%$ formalin for histological processing. To find out the histopathological changes of heart tissue, histological slides were prepared and were observed under microscope in the Department of Pathology, SSMC. Histological findings were categorized by scoring as mild, moderate and severe histological changes. The statistical analysis was done by one way ANOVA and Bonferroni test as applicable. Result: In this study, percent change from initial body weight to final body weight was significantly $(\mathrm{p}<0.01)$ lower both in CT-ISO-P and CT-ISO-C as compared to that of BC. Again, histological score was significantly $(p<0.01)$ higher in CT-ISO in comparison to that of BC. Moreover, these scores were significantly lower in CTISO-PRO $(\mathrm{p}<0.01)$, CT-ISO-P $(\mathrm{p}<0.05)$ and CT-ISO-C $(\mathrm{p}<0.05)$ in comparison to that of CT-ISO. Similarly, this score was significantly $(\mathrm{p}<0.01)$ lower in CT-ISO-C when compared to that of CT-ISO-P. Conclusion: The present study revealed that peanut can preserve almost normal histological architecture of heart tissue in isoproterenol induced cardiotoxic rats. However, the combined therapy of peanut with propranolol showed synergistic effect on preventing histological changes in heart tissue.
\end{abstract}

Key words: Peanut, Propranolol, Isoproterenol, Histology

Bangladesh Soc Physiol. 2014, June; 9(1): 22-30 For Authors Affiliation, see end of text.

http://www.banglajol.info/index.php/JBSP

\section{Introduction}

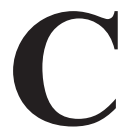
ardiotoxicity (CT) is the electrophysiological dysfunction of heart and myocardial damage ${ }^{1}$. It may be caused

Received March 2014; $\quad$ Accepted May 2014 by chemotherapy treatment with cytotoxic drugs such as doxorubicin, epirubicin, cisplatin etc, adverse effects of heavy metals intake like lead, cadmium etc, and an incorrectly administered 
drug such as high dose of isoproterenol and also by some cardiotoxins ${ }^{2}$.

Isoproterenol (ISO) is a sympathomimetic nonselective â-adrenergic receptor agonist used to produce myocardial injury in experimental animals for evaluation of various cardioprotective agents $^{3}$. High dose of isoproterenol causes severe oxidative stress in the myocardium resulting in infarction, it also generate free radicals and stimulate lipid peroxidation ${ }^{4}$.

Isoproterenol induced cardiotoxicity leads to severe histological changes in the myocardium due to free redical injury ${ }^{3}$. Histopathological examination of heart tissue showed disorganization of normal histological architecture of myocardium ${ }^{5}$. Loss of myocardial integrity, widespread necrosis with diffuse inflammation were observed by some investigators after using high dose of isoproterenol in their study ${ }^{6}$.

However, propranolol (PRO) is a non-selective â-blocker used in patients with hypertension, ischemic heart disease, cardiac arrhythmias and other cardiovascular diseases ${ }^{7}$. But long term use of propranolol may produce dyslipidemia, bradycardia, insomnia, light-headedness etc ${ }^{8}$.

Arachis hypogaea L. known as peanut belongs to the family of fabaceae have been valued for their high nutritional content throughout the world for many years ${ }^{9}$. Peanuts are energy dense foods that are particularly rich in fat, mostly unsaturated fatty acids and this unsaturated fatty acid of nuts through its lipid lowering effect may be responsible for their protective effects against ischemic heart disease ${ }^{10}$. Peanuts are also a rich source of vitamin-B, vitamin-E, magnesium, copper, phosphorus, plant protein, arginine, dietary fiber and numerous bioactive substances like flavonoids, resveratrol and plant sterols ${ }^{11}$. Peanut consumption is relatively safe but approximately $1 \%$ in the general population showed nut allergy ${ }^{12}$.

J Bangladesh Soc Physiol. 2014, June; 9(1): 22-30
Some researchers observed that consuming about an ounce of peanuts every day can reduce the risk of heart diseases by up to half ${ }^{13}$. Moreover, some other researchers found that consumption of peanut 5 times per week (about $155 \mathrm{~g}$ of nuts/week) reduced the risk of death from coronary heart diseases by $35 \%{ }^{14}$. Recently in an experimental study some researchers observed significant improvement in the histological structure in rats treated with conventional cardioprotective drug propranolol (â-blocker) along with Semecarpus anacardium (a species of nut closely related to cashew) nut extract in isoproterenol treated cardiotoxic rats ${ }^{15}$.

Therefore, the present study has been designed to observe the effect of peanut (Arachis hypogaea L.) and its combination with propranolol on the histological changes in heart tissue in isoproterenol induced cardiotoxic rats.

\section{Methods}

This experimental study was conducted in the Department of Physiology, Sir Salimullah Medical College (SSMC), Mitford, Dhaka from January to December 2012. The protocol of this study was approved by Institutional Ethics Committee (IEC) of SSMC. Twenty Wistar albino rats, age 85-100 days, weighing 120 to $150 \mathrm{~g}$ (initial body weight) were included in the experimental group (with peanut). They were sub-divided into CT-ISO-P (Cardiotoxic group with isoproterenol after peanut treatment) and CT-ISO-C (Cardiotoxic group with isoproterenol after combined treatment of peanut and propranolol). Age and weight matched 30 Wistar albino rats without any peanut supplementation was taken as control and subdivided into three sub-group, BC (baseline control), CT-ISO (Cardiotoxic group with isoproterenol) and CT-ISO-PRO (Cardiotoxic group with isoproterenol after propranolol treatment). Each subgroup consisted of 10 Wistar albino rats. Before grouping all the animals were acclimatized for 14 days under 12 hour dark and light cycle. During this study they had free access 
to food and water ad libitum. Each group consisted of 10 rats and was given basal diet for 21 consecutive days. In addition to this, animals of CT-ISO-PRO were given propranolol $(10 \mathrm{mg} /$ $\mathrm{kg}$ body weight; orally) for last seven (from $15^{\text {th }}$ to $21^{\text {st }}$ day of study period) consecutive days, animals of CT-ISO-P were given peanut extract $(500 \mathrm{mg} / \mathrm{kg}$ body weight; orally) for 21 consecutive days (started from $1^{\text {st }}$ day of study period), animals of CT-ISO-C were given both peanut extract $(500 \mathrm{mg} / \mathrm{kg}$ body weight; orally) for 21 consecutive days (started from $1^{\text {st }}$ day of study period) and propranolol $(10 \mathrm{mg} / \mathrm{kg}$ body weight; orally) for last seven (from $15^{\text {th }}$ to $21^{\text {st }}$ day of study period) consecutive days. All the groups of animals except baseline control group were given isoproterenol subcutaneously $(150 \mathrm{mg} /$ $\mathrm{kg}$ body weight/day) for last two (at $20^{\text {th }} \& 21^{\text {st }}$ day of study period) consecutive days. After acclimatization and before giving any supplementation, body weights of all the rats were measured (initial bw). After giving isoproterenol, propranolol and peanut all the animals including the baseline control rats, were anaesthetized with the help of chloroform (30\%) and sacrificed on $22^{\text {nd }}$ day. Before anaesthetized the rats on $22^{\text {nd }}$ day again body weights of rats (final bw) were taken. The heart samples were collected after sacrificing the rats. The heart was washed in ice cold saline and weighed by electric balance analyzer. The heart samples were preserved in $10 \%$ formalin for histological processing. To find out the histopathological changes of heart tissue, histological slides were prepared and were observed under microscope in the Department of Pathology, SSMC. Histological findings were categorized by mild, moderate and severe histological changes ${ }^{17}$. Statistical analysis were done by one way ANOVA and Bonferroni test by using SPSS windows, version 16.

Preparation of heart for histological examination: ${ }^{16}$ Heart tissue was taken in $10 \%$ formalin for overnight. Dehydration was carried out by keeping the tissue in ethanol (ranging from 70$100 \%$ ). After dehydration the heart sections was cleared in xylene and was kept in a paraffin bath and treated with melted paraffin at $70^{\circ} \mathrm{C}$ for one hour. Then the tissue was embedded in metallic moulds and was allowed to harden at room temperature to form paraffin blocks, cut into pieces to get tissue blocks, sectioned at $5 \mu \mathrm{m}$ thickness with a rotator microtome. Ribbons of section was placed in a hot water bath at $45-50^{\circ} \mathrm{C}$ and allowed to float and was taken on glass slides previously treated with adhesive and was dried.

Scoring: 15,17

The histological changes of heart tissue in experimental animals determined by scoring method depending on the severity where score 0 $=$ no change, score $1=$ mild change (small multifocal degeneration with slight degree of inflammation, scanty inflammatory cell infiltration, absence of hyalinization of muscle fiber, reduced interstitial space), score 2 = moderate change (extensive myofibrillar degeneration, mild necrosis with inflammation, mild hyalinization of muscle fiber, mild inflammatory cell infiltration), score 3 = marked change (widespread myocardial disorganization, hyalinization of muscle fiber, degeneration of myofibrils, infiltration of lymphocyte and macrophage, loss of integrity of myocardial cell membrane, necrosis with diffuse inflammation, increased interstitial space).

\section{Results}

The percent change of body weight from final to initial was significantly $(p<0.01)$ lower both in CT-ISO-P and in CT-ISO-C as compared to that of baseline control (Table I).

Again, the histological scores were significantly $(\mathrm{p}<0.01)$ higher in CT-ISO in comparison to that of baseline control group. Moreover, these scores were significantly $(\mathrm{p}<0.05)$ lower in CT-ISO-P and CT-ISO-C when compared to that of isoproterenol treated control group. Again, the scores were significantly $(\mathrm{p}<0.01)$ lower in CT-ISO-C in comparison to that of CT-ISO-P (Table III). 
Table I : Body weight in different groups of rats $(\mathrm{n}=50)$

\begin{tabular}{lccccc}
\hline Parameters & BC & Without peanut & & With peanut & Combined \\
& CT- ISO & CT- ISO-PRO & CT- ISO-P & CT-ISO-C \\
\hline Initial body wt (g)(Day 1) & $128.89 \pm 6.01$ & $132.78 \pm 10.93$ & $134.33 \pm 10.03$ & $135.73 \pm 5.35$ & $134.44 \pm 8.08$ \\
Final body wt (g)(Day 22) & $137.11 \pm 6.43$ & $147.83 \pm 11.06^{* * *}$ & $152.02 \pm 10.33^{* *}$ & $142.63 \pm 5.45^{*+}$ & $135.78 \pm 7.63^{\bullet++} \mathrm{o}$ \\
\% of change from final (F) & $6.39 \pm 1.67$ & $6.73 \pm 1.08$ & $6.06 \pm 0.93$ & $-1.64 \pm 1.07^{\wedge}-$ & $-3.24 \pm 4.46^{\wedge \wedge}$ - \\
to initial (I) body wt[(F-I)/Ix100] & & & & \\
\hline
\end{tabular}

Values are mean \pm SD. Statistical analysis was done by ANOVA test and then Bonferroni test. For final body wt $(* * * \mathrm{p}<0.01, * * \mathrm{p}<0.01 \& * \mathrm{p}<0.05$ BC vs CT-ISO, CT-ISO-PRO \& CT-ISO-P) $(\bullet \mathrm{p}<0.01$ CT-ISO vs CT-ISO-C) $\left({ }^{+} \mathrm{p}<0.05 \&{ }^{++} \mathrm{p}<0.01\right.$ CT-ISO-PRO vs CT-ISO-P \& CT-ISO-C) $\left({ }^{\circ} \mathrm{p}<0.01\right.$ CT-ISO-P vs CT-ISO-C). For $\%$ change of body wt $\left({ }^{\wedge} p<0.01 \&{ }^{\wedge} \mathrm{p}<0.01\right.$ BC vs CT-ISO-P \& CT-ISO-C) (" $p<0.01$ CT-ISO vs CT-ISO-C) (- $\mathrm{p}<0.01 \&-\mathrm{p}<0.01$ CT-ISO-PRO vs CT-ISO-P \& CT-ISO-C). BC $=$ Baseline control CT-ISO $=$ Cardiotoxic group with isoproterenol CT-ISO-PRO $=$ Cardiotoxic group with isoproterenol after propranolol treatment CTISO-P = Cardiotoxic group with isoproterenol after peanut treatment CT-ISO-C = Cardiotoxic group with isoproterenol after combined treatment of peanut and propranolol.

Table II: Histological observation of heart in different groups of rats $(\mathrm{n}=50)$

\begin{tabular}{|c|c|c|c|}
\hline Group & Observation & findings & Score \\
\hline $\begin{array}{l}\mathrm{BC}(\mathrm{n}=10) \\
\text { (Baseline control } \\
\text { group) }\end{array}$ & $\begin{array}{l}\text { Architecture of } \\
: \quad \text { Myocardium } \\
\text { - } \quad \text { Endocardium } \\
\text { - } \quad \text { Pericardium } \\
\text { Orientation of } \\
\text { : } \quad \text { Myocardial cell membrane } \\
\text { - } \quad \text { Nucleus } \\
\text { - Intercaleted disc }\end{array}$ & $\begin{array}{l}\text { Normal histological } \\
\text { findings }\end{array}$ & $\begin{array}{c}`^{\prime} 0 \\
\text { (normal) }\end{array}$ \\
\hline $\begin{array}{l}\text { CT-ISO }(\mathrm{n}=10) \\
\text { (Cardiotoxic group } \\
\text { with isoproterenol) }\end{array}$ & 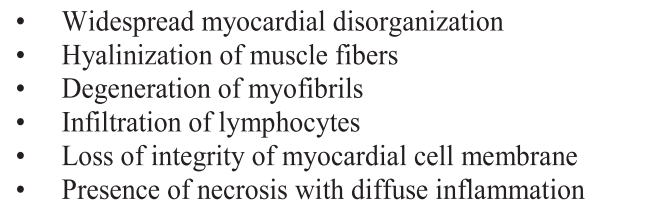 & $\begin{array}{l}\text { Marked } \\
\text { histological } \\
\text { changes }\end{array}$ & $\begin{array}{c}\text { '3' } \\
\text { (marked) }\end{array}$ \\
\hline $\begin{array}{l}\text { CT-ISO-PRO } \\
(\mathrm{n}=10) \\
\text { (Cardiotoxic group } \\
\text { with isoproterenol } \\
\text { after propranolol } \\
\text { treatment) }\end{array}$ & 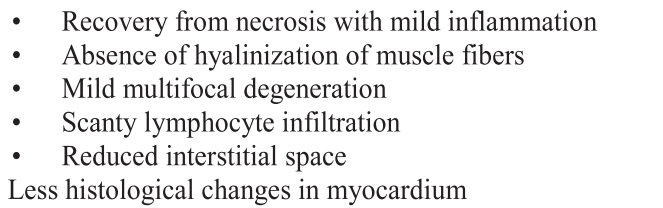 & $\begin{array}{l}\text { Normal histological } \\
\text { findings in } 5 \text { rats } \\
\text { and mild } \\
\text { histological } \\
\text { changes in } 4 \text { rats }\end{array}$ & $\begin{array}{l}\text { ' } 0 \text { ' } \\
\text { (normal) in } 5 \\
\text { rats } \\
\text { ' } 1 \text { ' } \\
\text { (mild) in } 4 \\
\text { rats }\end{array}$ \\
\hline $\begin{array}{l}\text { CT-ISO-P }(\mathrm{n}=10) \\
\text { (Cardiotoxic group } \\
\text { with isoproterenol } \\
\text { after peanut } \\
\text { treatment) }\end{array}$ & $\begin{array}{l}\text { - Recovery from necrosis with mild inflammation } \\
\text { - } \quad \text { Mild multifocal degeneration } \\
\text { - } \quad \text { Scanty lymphocyte infiltration } \\
\text { Less histological changes in myocardium }\end{array}$ & $\begin{array}{l}\text { Normal histological } \\
\text { findings in } 6 \text { rats, } \\
\text { mild histological } \\
\text { changes in } 2 \text { rats }\end{array}$ & $\begin{array}{l}\text { ' } 0 \text { ' } \\
\text { (normal)in } 6 \\
\text { rats } \\
\text { ' } 1 \text { ' } \\
\text { (mild) in } 2 \\
\text { rats }\end{array}$ \\
\hline $\begin{array}{l}\text { CT-ISO-C }(\mathrm{n}=10) \\
\text { (Cardiotoxic group } \\
\text { with isoproterenol } \\
\text { after combined } \\
\text { treatment of peanut } \\
\text { and propranolol) }\end{array}$ & $\begin{array}{l}\text { - Small multifocal degeneration } \\
\text { - } \\
\text { - Scanty inflammatory cell infiltration } \\
\text { - Fall in interstitial space } \\
\text { Restoration of normal architecture of myocardium }\end{array}$ & $\begin{array}{l}\text { Normal histological } \\
\text { findings in } 8 \text { rats, } \\
\text { mild histological } \\
\text { changes in } 1 \text { rat }\end{array}$ & $\begin{array}{l}\text { ' } 0 \text { ' } \\
\text { (normal) in } 8 \\
\text { rats } \\
\text { ' } 1 \text { ' } \\
\text { (mild) in } 1 \\
\text { rat }\end{array}$ \\
\hline
\end{tabular}


Table III : Distribution of rats by histological changes in heart $(\mathrm{n}=50)$

\begin{tabular}{lccccc}
\hline Histological & \multicolumn{3}{c}{ Without peanut } & With peanut & Combined \\
scores & $\mathrm{BC}$ & CT-ISO & CT-ISO-PRO & CT-ISO-P & CT-ISO-C \\
\hline Score '0'(\%) & $10(100.0)$ & $0(0)$ & $5(55.56)$ & $6(75.00)^{\bullet \bullet}$ & $8(88.89)^{+}$ \\
Score '1'(\%) & $0(0)$ & $0(0)$ & $4(44.44) \bullet \bullet$ & $2(25.00)$ & $1(11.11)$ \\
Score '2'(\%) & $0(0)$ & $0(0)$ & $0(0)$ & $0(0)$ & $0(0)$ \\
Score '3'(\%) & $0(0)$ & $9(100.00)^{* *}$ & $0(0)$ & $0(0)$ & $0(0)$ \\
\hline
\end{tabular}

Statistical analysis was done by Fisher's exact test. Figures in parentheses indicate percentage. For histological scores $\left({ }^{* *} \mathrm{p}<0.01 \mathrm{BC}\right.$ vs CT-ISO) $\left(\bullet \bullet \mathrm{p}<0.01, \bullet p<0.05 \& \bullet p<0.05\right.$ CT-ISO vs CT-ISO-PRO, CT-ISO-P \& CT-ISO-C) $\left({ }^{+} \mathrm{p}<0.01\right.$ CT-ISO-P vs CT-ISO-C). $\mathrm{BC}=$ Baseline control CT-ISO $=$ Cardiotoxic group with isoproterenol CT-ISO-PRO = Cardiotoxic group with isoproterenol after propranolol treatmen CT-ISO-P $=$ Cardiotoxic group with isoproterenol after peanut treatment CT-ISO-C = Cardiotoxic group with isoproterenol after combined treatment of peanut and propranolol.

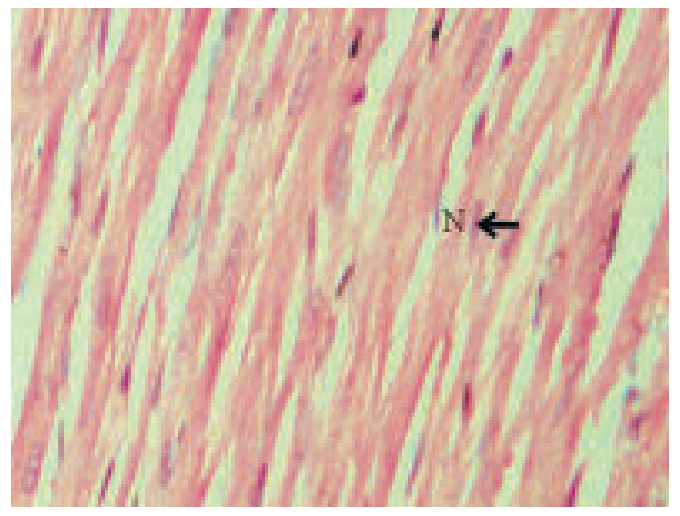

Figure 1: Normal histological architecture of heart tissue

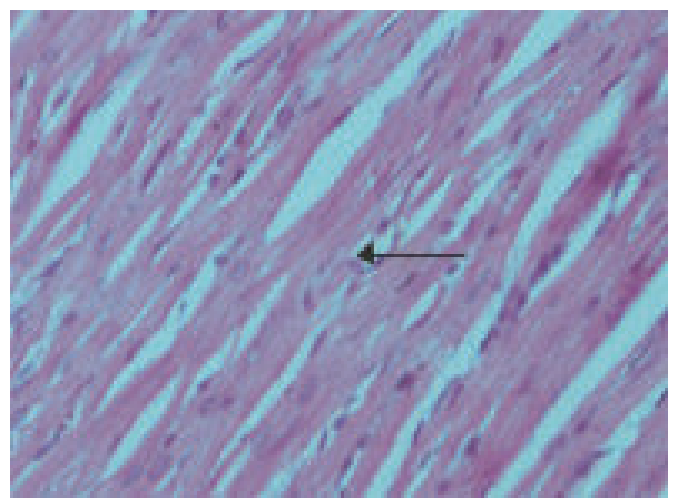

Figure 3: Scanty lymphocyte infiltration of mycocardium

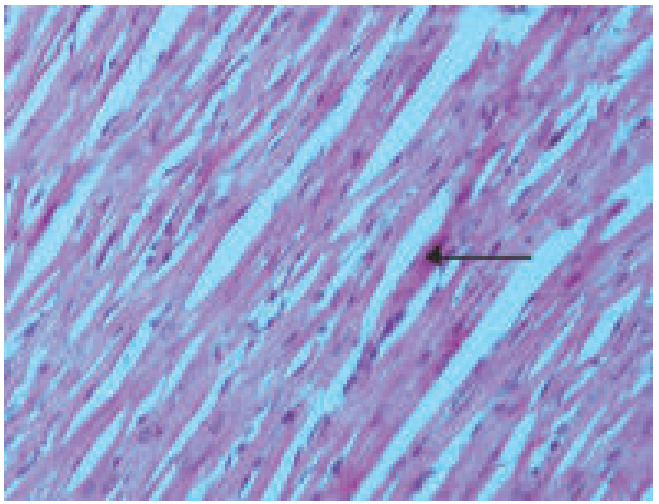

Figure 2: Mild multifocal degeneration of heart tissue

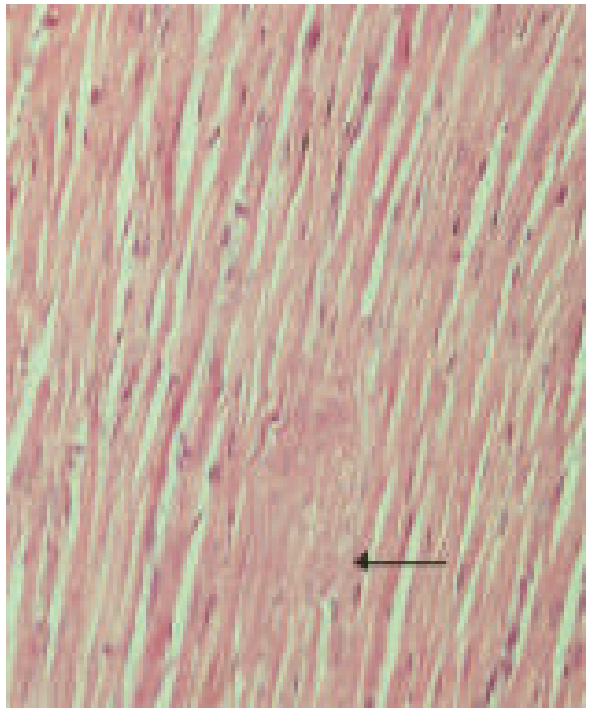

Figure 4: Widespread myocardial disorganization

J Bangladesh Soc Physiol. 2014, June; 9(1): 22-30 


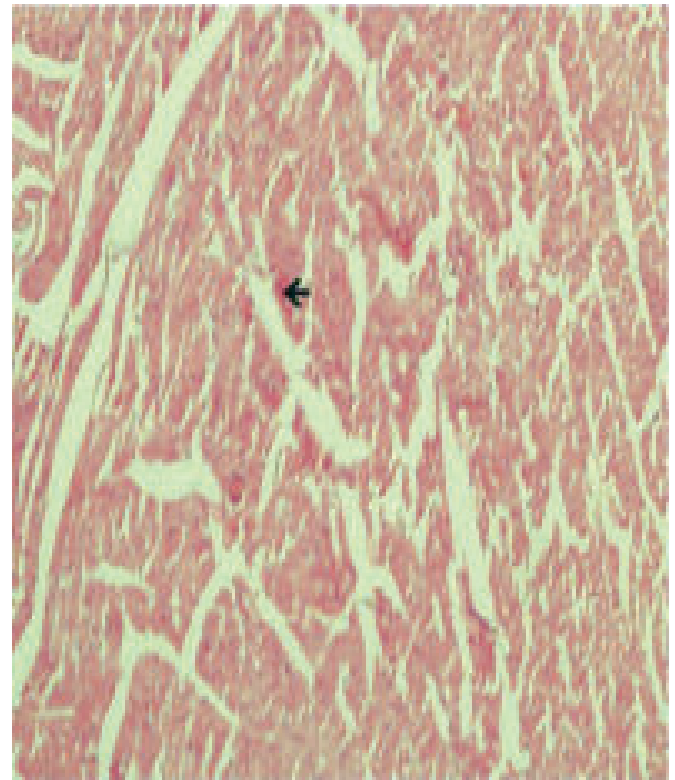

Figure 5: Degeneration of muscle fibers of heart

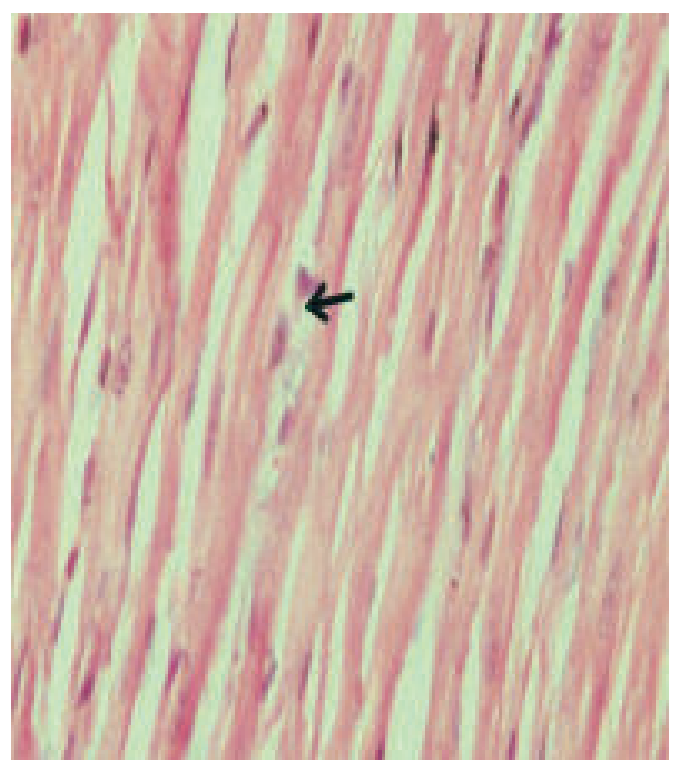

Figure 7: Lymphocytue infiltration of myocardium

\section{Discussion}

In the present study, the percent changes of body weight were almost similar to the findings reported by the various investigators from different countries ${ }^{15}$

Again, in this study marked histological changes such as widespread myocardial disorganization

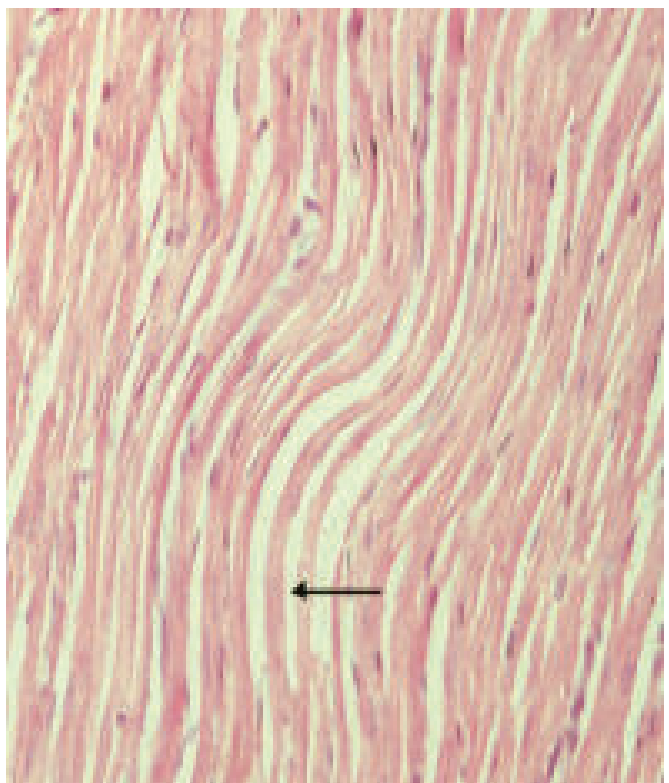

Figure 6: Hyalinization of muscle fibers of heart

(photomicrograph 4), degeneration of myofibrils (photomicrograph 5), hyalinization of muscle fibers (photomicrograph 6) and marked lymphocyte infiltration (photomicrograph 7) were observed in $100 \%$ of the rats in CT-ISO (Cardiotoxic group with isoproterenol). Similar type of observation was also made by some other researchers ${ }^{15,17}$. However, $55.56 \%$ of rats in CTISO-PRO (Cardiotoxic group with isoproterenol after propranolol treatment), $75 \%$ of rats in CTISO-P (Cardiotoxic group with isoproterenol after peanut treatment) and $88.89 \%$ of rats in CT-ISO$\mathrm{C}$ (Cardiotoxic group with isoproterenol after combined treatment of peanut and propranolol) showed almost normal histological architecture of heart (photomicrograph 1). Whereas, mild histological changes such as mild multifocal degeneration (photomicrograph 2), scanty lymphocyte infiltration (photomicrograph 3) was observed in rest of the rats. Different researchers of other countries observed almost similar type of findings by using different nuts and herbal plant $^{7}, 15$. On the contrary, some researchers observed that low dose of Tylophora indica herbal plant leaves failed to show any 
improvement in histological architecture of isoproterenol induced cardiotoxic rats ${ }^{18}$.

It has been postulated that, administration of high dose of isoproterenol subcutaneously induced diffuse myocardial necrosis and finally resulted in progressive cardiac enlargement ${ }^{19}$. However, rats that received isoproterenol at the dose of $150 \mathrm{mg} / \mathrm{kg}$ body weight showed marked inflammatory changes in the myocardium and visible ischemic lesion leads to cardiac hypertrophy and thereby increases weight of the heart ${ }^{15}$.

Again, high dose of isoproterenol causes lipid peroxidation of myocardial membrane through production of cytotoxic free radicals ${ }^{20}$. Isoproterenol also enhanced lipid biosynthesis in the myocardium by cardiac cAMP formation, which in turn leads to myocardial necrosis ${ }^{21}$. Some investigators reported that isoproterenol produces a number of biochemical and electrophysiological disturbances which ultimately causes disorganization of normal histological structure of the heart tissue ${ }^{22}$. Again, high dose of isoproterenol causes degeneration and necrosis of myocardial fibers, accumulation of inflammatory cells, hyalinization of muscle fibers etc due to increased production of free radicals ${ }^{17,18}$. Moreover, damage to cardiac musculature was also demonstrated and confirmed by histological scores ${ }^{15}$.

Again, some investigator suggested that propranolol causes dephosphorylation of myosin light chain kinase thereby decreases generation of oxygen free radicals ${ }^{18}$. Thus decreases lipid peroxidation of myocardial membrane, maintain myocardial integrity and presurve myocardial histological architecture ${ }^{7,15}$.

Furthermore, some other investigators observed that resveratrol, a poly-phenol phytoalexin present in peanut provide protection to myocardium via antioxidant activity ${ }^{23}$. Again, some investigators observed that peanut consumption significantly improve the antioxidant-oxidant status by increasing glutathione peroxidase (GSH) and decreasing thiobarbituric acid reactive substance (TBARS) levels ${ }^{24}$. High level of L-arginin and vitamine $\mathrm{E}$ content of peanut also have antioxidant activity and scavange oxygen free radicals thereby preserve normal histological architecture of heart $^{25}$.

In the present study, cardiotoxicity was observed in rats treated with isoproterenol as evidenced by widespread myocardial disorganization, degeneration of myofibrils, hyalinization of muscle fibers, lymphocyte infiltration and necrosis with diffuse inflammation of myocardium.

Again, fewer changes in histological architecture of heart such as recovery from necrosis with mild inflammation, absence of hyalinization of muscle fibers, mild multifocal degeneration and scanty lymphocyte infiltration in CT-ISO-P (Cardiotoxic group with isoproterenol after peanut treatment) and CT-ISO-C (Cardiotoxic group with isoproterenol after combined treatment of peanut and propranolol) of the present study suggested the cardioprotective role of peanut against isoproterenol induced cardiotoxicity. Moreover, in this study combined therapy of peanut and propranolol showed synergistic cardioprotective effect than when than were used alone. These effects are most likely due to anti-oxidant and free radical scavenging activity of peanut and propranolol. However, the exact mechanism involved in the cardioprotective activity of peanut against isoproterenol induced cardiotoxicity in rats cannot be find out from this type of study.

\section{Conclusion}

From this study, it can be concluded that peanut can prevent alterations of myocardial histological architectur due to its inhibition of generating and free radicals scavenging activity. However, combined therapy of peanut with propranolol showed synergistic effect on preventing cardiotoxicity by reducing free radical induced 
myocardial damage. It is also expected that the result of this study would make peanut acceptable among the people as a rich source of nutrients with medicinal value for the prevention of coronary heart diseases.

\section{Authors Affiliation}

- *Farah Naz, Assistant Professor, Department of Physiology, Green Life Medical College,Dhaka. Email: nazf188@gmail.com.

- Nasim Jahan, Professor \& Head, Department of Physiology, Sir Salimullah Medical College, Mitford, Dhaka. Email: prof.dr.nasimjahan@gmail.com.

- Nayma Sultana, Professor, Department of Physiology, Sir Salimullah Medical College, Mitford, Dhaka. Email: nayma_sultana@yahoo.com.

* for correspondence

\section{References}

1. Huang C, Zhang X, Ramil JM, Rikka S, Kim L, Lee Y, Gude NA, Thistlethwaite PM. Juvenile exposure to anthracyclines impairs cardiac progenitor cell function and vascularization resulting in greater susceptibility to stress induced myocardial injury in adult mice. Circulation 2010; 121(5): 675-683.

2. Schimmel K, Richel D, Brink RVD, Guchelaar HJ. Cardiotoxicity of cytotoxic drugs. Cancer Treatment Review 2004; 30: 181-191.

3. Sushma KS, Jaydeep A, Kumar JSS. Effect of carnitine on malondialdehyde, taurine and glutathione levels in heart of rats subjected to myocardial stress by isoproterenol. Ind J Exp Biol 1989; 27: 134-137.

4. Senthilkumar H, Anandan R, Devaki T, Santhoshkumar M. Cardioprotective effects of Picrorrhiza kurrora against isoproterenol induced myocardial stress in rats. Fitoterapia 2001; 72: 402-405

5. Vibha L, Asdaq SMB, Nagpal S, Rawri RK. Protective effect of medicinal garlic against isoprenaline induced myocardial infarction in rats. International Journal of Pharmacology 2011; 7(4): 510-515.

6. Sing PN, Athar MS. Simplified calculation of mean QRS vector (mean electrical axis of heart) of electrocardiogram. Indian Journal Physiol Pharmacol 2003; 47:212.

7. Asdaq SMB, Inamdar MN. Pharmacodynamic and pharmacokinetic interactions of propranolol with
Garlic (Allium sativum) in rats. Evidence Based Complementary and Alternative Medicine 2011; Article ID. 824042: 11.

8. Hoffman BB. Adrenoceptor antagonist drugs in Katzung BG. Basic and Clinical Pharmacology. $8^{\text {th }}$ ed. The McGraw Hill Companiesz: Amarica 2001; 138-152.

9. Higgs J. The beneficial role of peanuts in the dietpart 2. Nutrition \& Food Science 2003; 33(2): 56-64.

10. Sabate J. Does nut consumption protect against ischemic heart disease?. European Journal of Clinical Nutrition 1993; 47(1): S71-S75.

11. Griel AE, Eissenstat B, Juturu V, Hsieh G, KrisEtherton PM. Improved diet quality with peanut consumption. J Am Coll Nutr 2004; 23(6): 660-668.

12. Crespo JF, James JM, Fernandez-Rodriguez C, Rodriguez J. Food allergy: nuts and tree nuts. Br J Nutr 2006; 96: 95-102.

13. Fraser GE, Sabate J, Beeson WL, Strahan TM. A possible protective effect of nut consumption on risk of CHD. Archives of Internal Medicine 1992; 152: 1416-1424.

14. Hu FB, Stampfer MJ, Manson JE, Rimm EB, Colditz GA, Rosner BA, Speizer FE, Hennekens CH, Willett WC. Frequent nut consumption and risk of coronary heart disease in women: prospective cohort study. British Medical Journal 1998; 317 : $1341-1345$

15. Chakraborty M, Asdaq SMB. Interaction of Semecarpus anacardium L. with propranolol against isoproterenol induced myocardial damage in rats. Indian Journal of Experimental Biology 2011; 49: 200-206.

16. Asdaq SMB, Inamdar MN, Asad M, Nanjundan PK. Interaction of propranolol with garlic in isoproterenol induced myocardial infraction in rat. Journal of Pharmacology and Toxicology 2008; 3(6): 414-424.

17. Ojha S, Bharti S, Golechha M, Sharma AK, Rani N, Kumari S, Arya DS. Andrographis paniculata extract protect against isoproterenol induced myocardial injury by mitigating cardiac dysfunction and oxidative injury in rats. Acta Poloniae Pharmaceutica-Drug Research 2012; 69(2): 269-278.

18. Asdaq SMB, Sowmya SK. Effect of hydroalcoholic extracts of Tylophora indica leaves in isoprenaline 
induced myocardial damage in rat heart. IJPT 2010; 9(1): 15-20.

19. Teerlink JR, Pfeffer JM, Pfeffer MA. Progressive ventricular remodeling in response to diffuse isoproterenol induced myocardial necrosis in rats. Circ Res 1994; 75: 105-113.

20. Ajitha M, Rajnaryana K. Role of oxygen free radicals in human disease. Indian Drugs 2001; 38: 545 .

21. Pritha I, Devi SCS. Effect of tocopherol on lipid peroxidation in isoproterenol induced myocardial infarction in rats. Indian J Physiol Pharmacol 1997; 41: 369 .

22. Upaganlawar A, Gandhi H, Balaraman R. Isoproterenol induced myocardial infarction: protective role of natural products. Journal of Pharmacology and Toxicology 2011; 6(1): 1-17.

23. Wolter F, Akoglu B, Clausnitzer A, Stein J. Downregulation of the cyclin D1/Cdk4 complex occurs during resveratrol induced cell cycle arrest in colon cancer cell lines. J Nutr 2001; 131: 2197-2203.

24. Emekli-Alturfan E, Kasikci E, Yarat A. Peanuts improve blood glutathione, HDL-cholesterol level and change tissue factor activity in rats fed a high cholesterol diet. Eur J Nutr 2007; 46: 476-482.

25. Kris-Etherton PM, Yu-Poth S, Sabate J, Ratcliffe HE, Zhao G, Etherton TD. Nuts and their bioactive constituents: effects on serum lipids and other factors that affect disease risk. Am J Clin Nutr 1999; 70(suppl): 504S-511S. 